\title{
Tipo Tátil: material de ensino de tipografia para deficientes visuais
}

\author{
Tactile Type: teaching material for the visually impaired
}

\author{
Luciana Eller Cruz, Virgínia Tiradentes Souto
}

Tipografia, acessibilidade,

O objetivo deste artigo é descrever um estudo sobre o ensino de tipografia para pessoas deficiência visual, tato com deficiência visual. A pesquisa propõe o desenvolvimento de um material didático que tem como objetivo permitir que os deficientes visuais conheçam mais sobre a tipografia através do tato. $\mathrm{O}$ artigo apresenta os estudos feitos com os deficientes visuais para o desenvolvimento deste material. Os estudos demonstram que o kit Tipo Tátil pode auxiliar no ensino de tipografia a deficientes visuais.

Typography, accessibility, visual impairment, touch
The purpose of this article is to describe a study on the teaching of typography for visually impaired people. The research proposes the development of a didactic material that aims to enable the visually impaired to know more about typography through touch. The article presents the studies done with the visually impaired for the development of this material. The studies show that the 'Tactile Type' kit can aid in the teaching of typography to the visually impaired.

\section{Introdução}

De acordo com o Censo Demográfico de 2010 (Brasil, 2010: 114) mais de 500 mil brasileiros não conseguiam enxergar de modo algum, enquanto mais de 6 milhões enxergavam com grande dificuldade. Ao todo, mais de 6,55 milhões de brasileiros teriam grande dificuldade em usufruir de qualquer bem, serviço ou ambiente que demande fortemente a boa visão para ser utilizado.

A inclusão social dos deficientes visuais passa comumente pela remoção de obstáculos físicos, pela sinalização tátil ou auditiva e pela adoção de comunicação em Braille ou auditiva. Existe hoje um grande número de iniciativas para prover condições mais favoráveis para o uso de bens, serviços e ambientes para deficientes visuais, como por exemplo o Art Education for the Blind (Art beyond sight, 2005), e o Centro Argentino de Teatro Cego (Aguiar Buenos Aires, 2017).

É válido notar também que estes projetos atuam com o intuito de diminuir a exclusão social e cultural do deficiente visual por meio da 
aproximação deste com as experiências que os videntes vivem em seu cotidiano. Nesse sentido, percebe-se que ainda há uma distanciação entre a experiência do deficiente visual e a do vidente em relação à tipografia, uma vez que os deficientes visuais possuem poucos recursos para o aprendizado sobre essa área.

Por exemplo, usando a visão, é possível diferenciar uma letra escrita à mão de um tipo impresso. As fontes usadas em convites para cerimônias (e.g. casamentos, formaturas) não serão as mesmas adotadas em um relatório científico. A tipografia está presente no diaa-dia. Qualquer tipo de escrita carrega em si informações visuais que podem refletir valores, ideias e até estados de ânimo. Entretanto, tais informações em geral estarão fora do alcance e passarão despercebidas pelos deficientes visuais.

A adaptação da informação visual por meio de outros sentidos é muito importante para pessoas com deficiências, como por exemplo o tato. De acordo com Sá, Campos, \& Silva (2007) as crianças cegas operam conceitos "que tem significado real para elas a partir de suas experiências”, e conceitos “que fazem referência a situações visuais”. As autoras recomendam o uso de relevos em desenhos, gráficos e ilustrações tanto no material didático como em avaliações.

Formas de áudio-descrição ou Braille podem descrever conteúdos, mas não são adequados para descrever a tipografia. Mesmo que um conteúdo textual possa ser traduzido em Braille ou áudio, o conteúdo informacional expresso na tipografia utilizada não pode ser facilmente traduzido em Braille ou áudio, havendo perda de parte significativa do conteúdo que se desejava transmitir, pois há informações que são passadas unicamente por meio da tipografia adotada.

O objetivo deste artigo é descrever um estudo sobre o ensino de tipografia para pessoas com deficiência visual. A pesquisa propõe o desenvolvimento de um material didático que tem como objetivo permitir que os deficientes visuais conheçam mais sobre a tipografia por meio do tato. $\mathrm{O}$ artigo apresenta os estudos feitos com os deficientes visuais para o desenvolvimento deste material.

\section{Desenvolvimento de um objeto de ensino de tipografia para deficientes visuais}

Ensinar tipografia a pessoas com deficiência visual pode ser extremamente útil e inclusivo por abrir a esses concidadãos o mundo da tipografia e a comunicação simbólica e estética que esse mundo abarca.

O projeto tem como objetivo a criação de um material de ensino de tipografia a deficientes visuais. Esse material consiste de uma parte tátil, placas e letras táteis, e uma parte escrita, isto é, o material pedagógico contendo a história da tipografia contextualizada na história do mundo, passando por nove categorias de tipografias distintas. 
A classificação VoxTypi foi utilizada como base nas escolhas dos tipos que fazem parte do produto final. Esta classificação foi proposta em 1962 pela ATypI (Association Typographique Internationale)

(Silva e Farias, 2005) e é considerada consagrada (Finizola e Coutinho, 2009), além de ter forte base histórica (Childers, Griscti, \& Leben, 2013).

O projeto foi desenvolvido em duas etapas e se estendeu por um ano e meio. Inicialmente, foi desenvolvida uma proposta de placas de MDF, com espaço para encaixe da letra tridimensional, com gravação de linhas-guia na parte frontal e gravação do nome da fonte na parte posterior.

Nesta primeira fase do projeto foram realizados testes com dois usuários deficientes visuais. Os usuários perceberam todas as características apresentadas, reconhecendo a diferença entre maiúsculas e minúsculas e a diferença entre as fontes, porém também não reconheceram as linhas guia (Figura 1 ). O desenvolvimento da primeira parte deste projeto foi publicado no SIGRaDI, Sociedad Iberoamericana de Gráfica Digital.

Figure 1 Alterativa 1- segundo teste de usabilidade com usuário.
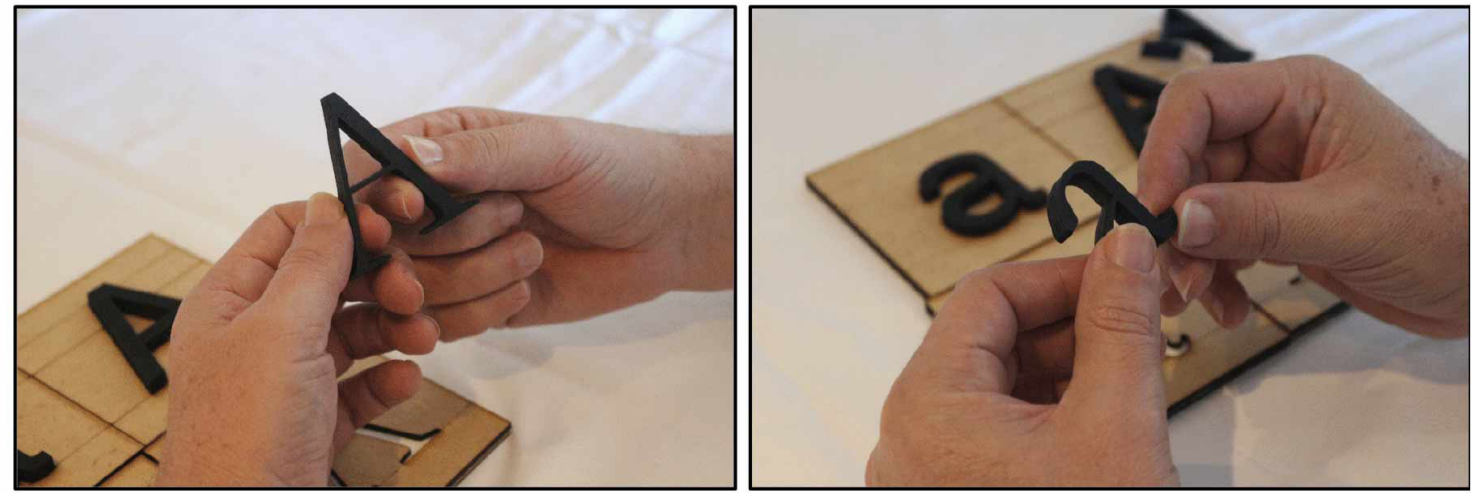

A partir desta proposta inicial e dos testes realizados foram feitos ajustes na proposta e novos testes de usabilidade com deficientes visuais, descritos a seguir.

\section{Alterações da proposta a partir dos testes com os deficientes visuais}

A partir da alternativa desenvolvida previamente, foi concebida a segunda versão do material tátil, como identificado na Figura 2, com as seguintes mudanças: 
- inclusão do texto em Braille contendo qual a letra e à qual fonte pertence;

- inclusão de todas as linhas guia (linha de base, linha das descendentes, linha das ascendentes, linha média);

- aumento da espessura das linhas guia.

Figure 2 Desenho técnico do segundo protótipo.

FRENTE

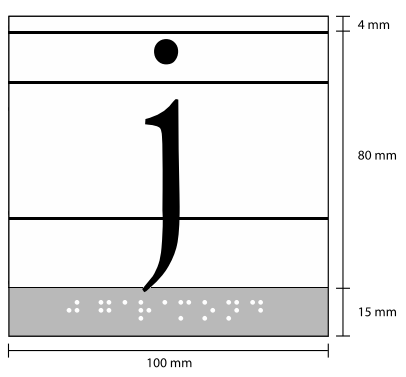

VERSO

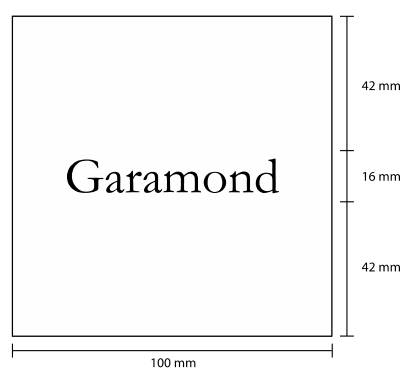

Foram realizadas modificações na proposta com o intuito de criar um modelo único, que pode ser usado para qualquer letra de qualquer fonte. Para isso foram incluídas todas as linhas guia dentro do espaço da placa e ficou determinado que o tamanho da letra inserida seria medido em milímetros e não em pontos. O espaço determinado para a disposição da letra é de $80 \mathrm{~mm}$ x 100mm.

Essa versão foi então submetida a um teste de usabilidade para sua validação, como mostra a Figura 3. O usuário, que é cego total, relatou:

- Dificuldade em ler o Braille, pois estava com pouco relevo;

- Conseguiu perceber de forma tátil a letra, mas não tinha conhecimento prévio de como era a sua forma.

- Percebeu as linhas guia

- Teve grande dificuldade de encaixe

- Linha das descendentes em interferência com a área do Braille;

Figure 3 Alternativa 2 - teste de usabilidade com usuário.

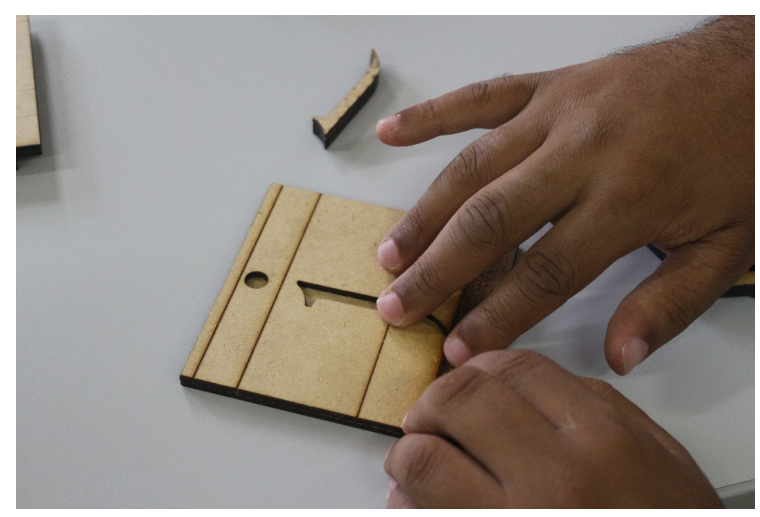


Foi realizado também um teste com nove tipografias distintas afim de saber se o usuário conseguiria distinguir as características da mesma letra em diferentes formas, como apresentado na Figura 4.

Figure 4 Alternativa 2 - teste de usabilidade com usuário.

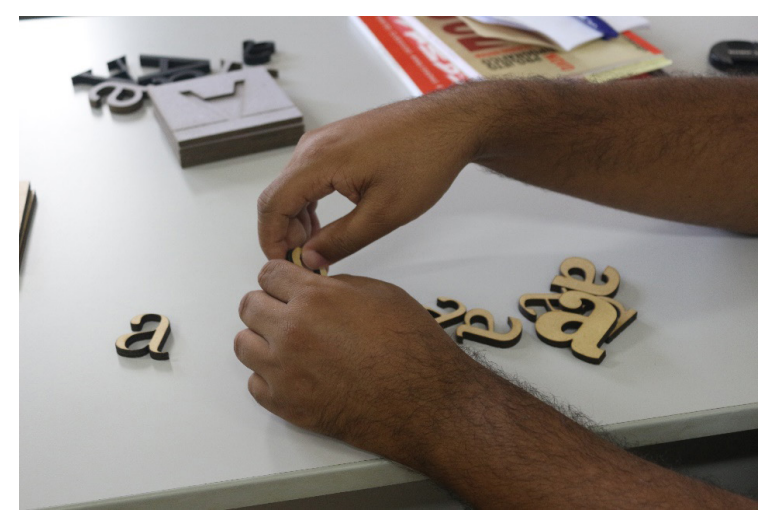

O usuário não conhecia a forma da letra e teve dificuldade em entender a orientação correta e identificar as formas como representando a mesma letra.

Foi constatado, na ocasião, por meio de entrevista informal, que existe grande diferença entre o deficiente visual congênito, ou seja, que já nasceu cego e aquele que perdeu a visão posteriormente já na fase adulta.

Ficou claro, por meio desta entrevista, a alta complexidade do projeto. O conhecimento sobre tipografia presume o conhecimento prévio da forma das letras, o qual não é bem estabelecido. Sendo necessário previamente ensinar o básico da escrita e forma das letras e posteriormente se aprofundar no conhecimento da tipografia.

Foi criado o terceiro modelo (Figura 5), no qual os seguintes problemas foram corrigidos:

- Linha das descendentes em interferência com a área do Braille;

- Braille com pouco relevo, dificultando a leitura.

Figure 5 Desenho técnico do terceiro protótipo.

FRENTE

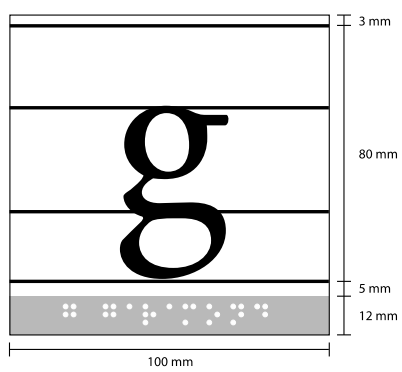

VERSO

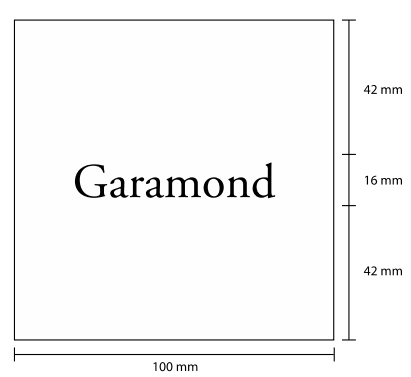


A questão do relevo foi resolvida com o aumento da potência na máquina laser. Desta forma mais material é subtraído, deixando o relevo mais evidente.

Um teste foi realizado para averiguar se os problemas identificados persistiam. Ele consistia na validação da placa tátil e também das letras cortadas de tipografias distintas, como mostra a Figura 6.

Figure 6 Alternativa 3 - teste de usabilidade com usuário.

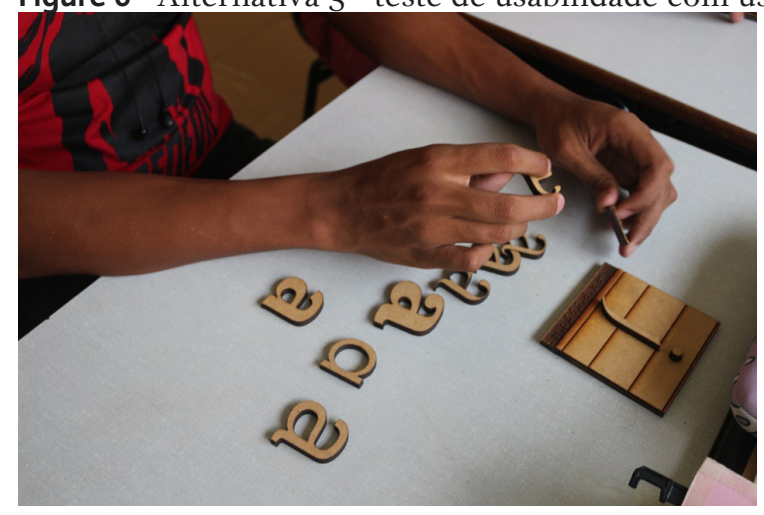

O teste comprovou que os problemas de relevo e de interferência foram solucionados, porém a dificuldade de encaixe e a falta de familiarização com a forma das letras persistiu.

Tendo em consideração todos os aspectos apresentados pelos voluntários durante os testes, decidiu-se por uma reformulação do projeto, criando novos materiais auxiliares e dividindo as letras em seções.

É necessário mostrar não somente as diferenças entres as formas de uma mesma letra, mas como são as letras em si, e apresentar também conceitos básicos de tipografia e termos técnicos. Por isso foram geradas várias placas com objetivos específicos, que formam um único sistema de ensino de tipografia.

A alternativa final contém placas de letras fixas e letras móveis de todo o alfabeto com maiúsculas e minúsculas, que serão armazenadas dentro de uma caixa com divisórias, além do material auxiliar pedagógico.

A placa de escala de pontos, Figura 7, é um material pedagógico relacionando a escala de pontos à escala em centímetros. Ambos são unidades de medida, sendo pontos a unidade padrão para tamanho de tipos. Ao relacionar de forma prática letras em alto relevo com seu tamanho em pontos e em centímetros, o aprendizado do que são pontos se torna concreto. 
Figure 7 Protótipo da placa de escala de pontos.

\section{Placa de escala de pontos}

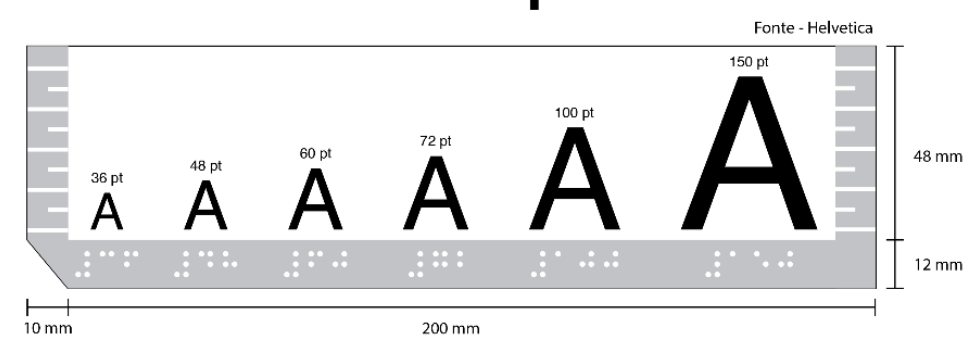

A placa de ascendentes (Figura 8) coloca em ordem alfabética todas as letras do alfabeto latino - português que possuem letras com partes ascendentes.

Figure 8 Protótipo da placa de ascendentes.

\section{Placa de ascendentes}

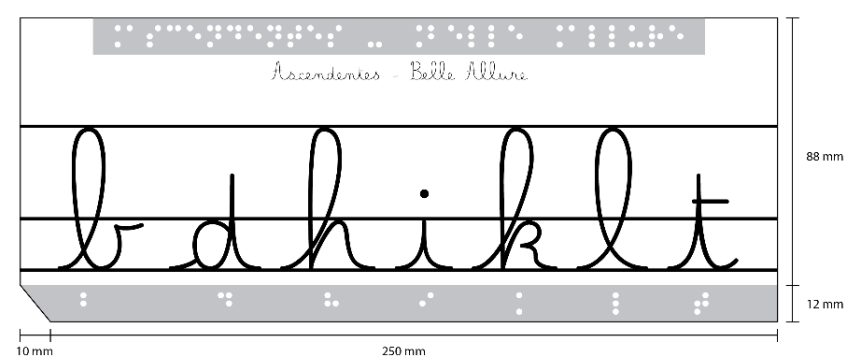

A placa de escala de pontos foi testada por dois usuários e foram relatados as seguintes questões:

- Foi bem entendida a gradação em pontos

- O fonte Braille usada não seguia a grafia correta da escrita

- A regra em centímetros nas laterais não foi entendida

A placa de ascendentes foi testada, como mostra a Figura 9, e foram expostas as seguintes questões:

- O tamanho das letras estava legível e agradável

- A grafia do Braille estava correto, porém o tamanho estava fora do padrão

- O corte diagonal deve estar presente todas as vezes que houver Braille para indicar o sentido da leitura

- As letras ficaram finas e frágeis 
Figure 9 Protótipo da placa de escala de pontos.

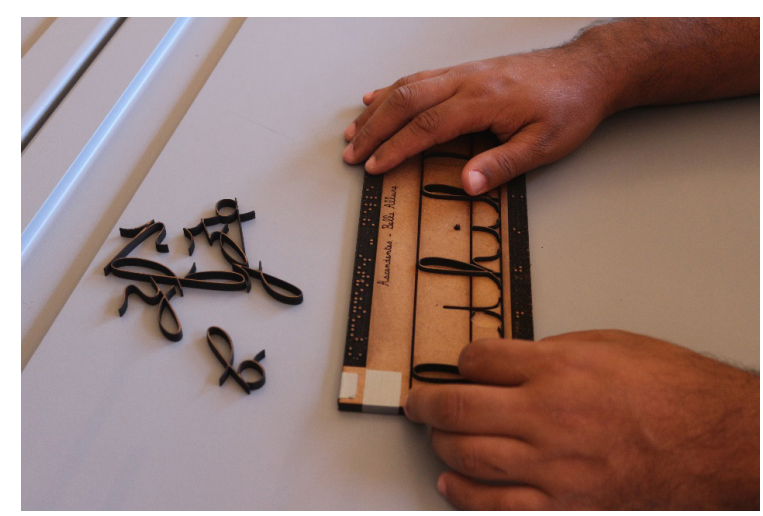

Complementarmente, foi testado um protótipo de caixa para verificar a ergonomia e como se daria a orientação, como seriam distribuídos os elementos e como seriam encontrados (Figura 10).

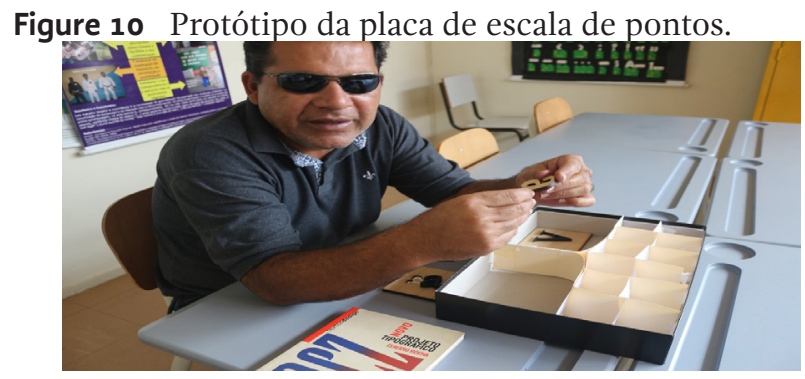

\section{Considerações finais}

Os estudos demostram que o kit Tipo Tátil pode ser utilizado como um material de ensino de tipografia a deficientes visuais. Foi verificado que os usuários que nunca haviam enxergado ou que enxergaram por um período breve, que não conheciam a forma das letras do alfabeto latino tinham dificuldade em entender certos conceitos e memorizar formas, pela falta de familiaridade com tal sistema de escrita, mas a recíproca não é verdadeira. Aqueles que haviam enxergado antes não apresentaram melhora significativa no reconhecimento das letras, apesar de terem tido experiências visuais com a forma das letras.

Os usuários que tiveram contato mais de uma vez com o material demonstraram melhora no entendimento dos conceitos e também no reconhecimento tátil. O material pedagógico em conjunto com o material tátil foi de extrema importância para a fixação de conceitos, sendo o método mais eficiente de ensino. Aplicações 
relacionando com objetos do dia-a-dia e elementos da cultura popular também se mostraram eficazes criando links entre o conhecimento novo e o antigo.

Acredita-se que com a implementação de todas as partes do produto, placas e texto, a tendência é que os usuários se familiarizem cada vez mais com as formas das diferentes tipografias.

Como proposta para trabalhos futuros, acredita-se que a complementação do produto com um sistema automatizado para guiar o usuário durante o processo de uso gerará ainda um melhor resultado. Permitindo assim que a utilização do produto seja feita sem necessidade de auxílio externo.

\section{Agradecimento}

Agradecemos aos participantes desta pesquisa.

\section{Referências}

AGUIAR BUENOS AIRES. 2017. Teatro Ciego: conheça o teatro totalmente no escuro. AGUIAR Buenos Aires, 2017. Disponivel em: <http:// aguiarbuenosaires.com/teatro-ciego/>. Acesso em: 22 jun. 2017.

ART BEYOND SIGHT. 2005. About Art Education for the Blind. Art Education for the Blind, 2005. Disponivel em: <http://www.artbeyondsight.org/sidebar/ aboutaeb.shtml>. Acesso em: 22 jun. 2017.

CHILDERS, T.; GRISCTI, J.; LEBEN, L. 2013. 25 systems for classifying typography: a study in naming frequency. Parsons Journal for Information Mapping, The Parsons Institute for Information Mapping, v. 5, n. 1, p. 1-22, winter 2013. Disponivel em: <http://luc.devroye.org/ParsonsJournalForInfor mationMapping-Childers+Griscti+Leben-2013.pdf>. Acesso em: 22 jun. 2017.

FINIZOLA, F. COUTINHO, S. G. 2009. Em busca de uma classificação para os letreiramentos populares. InfoDesign Revista Brasileira de Design da Informação 6 - 2 [2009] 16-29.

IBGE. 2010. Censo Demográfico 2010 - Características gerais da população, religião e pessoas com deficiência. Rio de Janeiro: IBGE, 2010. Rio de Janeiro: IBGE, 2010.

SÁ, E. D. D.; CAMPOS, I. M. D.; SILVA, M. B. C. 2007. Formação continuada a distância de professores para o atendimento educacional especializado: Deficiência Visual. Brasília: SEESP/SEED/MEC, 2007. Disponivel em: <http://portal.mec.gov.br/seesp/arquivos/pdf/aee_dv.pdf>. Acesso em: 22 jun. 2017.

SILVA, F. L: C. M.; FARIAS, P. L. 2005. Um panorama das classificações tipográficas. Estudos em Design, v. 11, n. 2, p. 67-81. 


\section{Sobre os autores}

\section{Luciana Eller Cruz}

<lucianaeller14@gmail.com>

Graduada, UnB, Brazil

Departamento de Design

Instituto de Artes

Universidade de Brasília

Campus Universitário Darcy Ribeiro

ICC Norte, Módulo 18

Brasília, DF, Brasil - CEP 70910-900

\section{Virgínia Tiradentes Souto}

< v.tiradentes@gmail.com>

PhD, UnB, Brazil

Departamento de Design

Instituto de Artes

Universidade de Brasília

Campus Universitário Darcy Ribeiro

ICC Norte, Módulo 18

Brasília, DF, Brasil - CEP 70910-90

Artigo recebido em 26/10/2017

Artigo aceito em 26/10/2017 